\title{
"Two hits - one stone"; increased efficacy of cisplatin-based therapies by targeting PCNA's role in both DNA repair and cellular signaling
}

\author{
Caroline Krogh Søgaard ${ }^{1,3, *}$, Augun Blindheim ${ }^{1,2, *}$, Lisa M. Røst ${ }^{4}$, Voin Petrović ${ }^{1}$, \\ Anala Nepal ${ }^{1}$, Siri Bachke ${ }^{1}$, Nina-Beate Liabakk ${ }^{1}$, Odrun A. Gederaas ${ }^{1}$, Trond Viset $^{5}$, \\ Carl-Jørgen Arum ${ }^{1,2}$, Per Bruheim ${ }^{4}$ and Marit Otterlei ${ }^{1,3,6}$ \\ ${ }^{1}$ Department of Clinical and Molecular Medicine, Norwegian University of Science and Technology (NTNU), Trondheim, Norway \\ ${ }^{2}$ Department of Urology and Surgery, St. Olavs Hospital, Trondheim University Hospital, Trondheim, Norway \\ ${ }^{3}$ Clinic of Surgery, St. Olavs Hospital, Trondheim University Hospital, Trondheim, Norway \\ ${ }^{4}$ Department of Biotechnology and Food Science, NTNU, Trondheim, Norway \\ ${ }^{5}$ Department of Pathology, St. Olavs Hospital, Trondheim University Hospital, Trondheim, Norway \\ ${ }^{6}$ APIM Therapeutics A/S, Trondheim, Norway \\ *These authors have contributed equally to this work \\ Correspondence to: Marit Otterlei, email: marit.otterlei@ntnu.no \\ Keywords: muscle-invasive bladder cancer; APIM-peptide; cellular signaling; DNA repair; cisplatin resistance \\ Received: June 06, $2018 \quad$ Accepted: July 31, $2018 \quad$ Published: August 21, 2018 \\ Copyright: Søgaard et al. This is an open-access article distributed under the terms of the Creative Commons Attribution License \\ 3.0 (CC BY 3.0), which permits unrestricted use, distribution, and reproduction in any medium, provided the original author and \\ source are credited.
}

\section{ABSTRACT}

Low response rate and rapid development of resistance against commonly used chemotherapeutic regimes demand new multi-targeting anti-cancer strategies. In this study, we target the stress-related roles of the scaffold protein PCNA with a cellpenetrating peptide containing the PCNA-interacting motif APIM. The APIM-peptide increased the efficacy of cisplatin-based therapies in a muscle-invasive bladder cancer (MIBC) solid tumor model in rat and in bladder cancer (BC) cell lines. By combining multiple omics-levels, from gene expression to proteome/kinome and metabolome, we revealed a unique downregulation of the EGFR/ERBB2 and PI3K/Akt/mTOR pathways in the APIM-peptide-cisplatin combination treated cells. Additionally, the combination treatment reduced the expression of anti-apoptotic proteins and proteins involved in development of resistance to cisplatin. Concurrently, we observed increased levels of DNA breaks in combination treated cells, suggesting that the APIM-peptide impaired PCNA - DNA repair protein interactions and reduced the efficacy of repair. This was also seen in cisplatin-resistant cells, which notably was re-sensitized to cisplatin by the APIM-peptide. Our data indicate that the increased efficacy of cisplatin treatment is mediated both via downregulation of known oncogenic signaling pathways and inhibition of DNA repair/translesion synthesis (TLS), thus the APIM-peptide hits both nuclear and cytosolic functions of PCNA. The novel multi-targeting strategy of the APIM-peptide could potentially improve the efficacy of chemotherapeutic regiments for treatment of MIBC, and likely other solid tumors. 


\section{INTRODUCTION}

$\mathrm{BC}$ is the ninth most common cancer worldwide, with an expected increase in incidence [1]. MIBC contributes to $30 \%$ of $\mathrm{BC}$ patients, and the 5 -year survival rate after cystectomy is only $50 \%$ [2]. There have been few improvements in therapy since the advent of cisplatin. Immunotherapy via PD-1 inhibition is the only novel treatment recently accepted for MIBC, but the improvement in survival is so far modest [3]. Recent advances in genomic research have identified several therapeutic targets, however, their efficacy in therapy remains to be tested [4].

The gold standard in MIBC therapy is neoadjuvant cisplatin-containing treatment and cystectomy. Cisplatinbased chemotherapy is also the first line treatment for patients with metastatic disease, where gemcitabine/ cisplatin (GC) and methotrexate/vinblastine/adriamycin/ cisplatin (MVAC) are the main chemotherapeutic alternatives [2]. Formation of DNA interstrand crosslinks are responsible for the major cytotoxicity of cisplatin, but increased DNA repair, overexpression of ERBB2 and activation of the PI3K/Akt pathway often contributes to development of cisplatin resistance [5]. Cisplatin may offer longer survival, nonetheless, long term survival is uncommon in metastatic disease [6]. Cisplatin sensitization via strategies that can reduce cisplatin resistance can potentially improve metastatic as well as non-metastatic MIBC therapy.

PCNA acts as scaffold protein in several essential processes such as DNA replication, DNA repair and epigenetics [7, 8]. More recently, cytosolic scaffold roles of PCNA in apoptosis, glycolysis and signaling have been demonstrated [8-11]. The essential roles of PCNA during cellular stress and replication makes it a potential drug target, and a few PCNA-targeting drugs are under preclinical development [12].

The two known, and highly conserved, PCNAinteracting motifs, the PCNA-interacting peptide (PIP)box and AlkB homologue 2 PCNA-interacting motif (APIM), are present in more than 600 proteins, and share the same binding site on PCNA [13-16]. Peptides and/or small molecules that bind with high affinity to this binding site will inhibit the majority of PCNA-protein interactions, and thereby inhibit essential cellular functions. Thus, such drugs will be cytotoxic to all cells. Accordingly, overexpression of a high affinity (canonical) PIP-box peptide is cytotoxic. On the other hand, overexpression of an APIM-peptide is well tolerated in the same cells in the absence of exogenous stress, but it strongly reduces cell growth and induces apoptosis in cells stressed with DNA damaging agents $[10,14,17]$. This is in line with the presence of APIM in many proteins involved in cellular stress responses, including the nucleotide excision repair (NER) protein XPA, the TLS polymerase POL $\zeta$ and proteins such as RAD51B, Topo IIa, TFII-I, ZRANB3 and FBH1, all which are important during replication stress and involved in repair of cisplatin-induced DNA lesions [14, 18-22]. Furthermore, the APIM-peptide is shown to enhance the efficacy of various chemotherapeutic drugs in multiple cancer cells both in vitro and in vivo, i.e. i) in a multiple myeloma xenograft model and an endogenous orthotopic prostate cancer model after intraperitoneal administration in combination with melphalan and docetaxel [10, 23], ii) in both syngeneic and endogenous orthotopic non-MIBC models in rats after intravesical administrations in combination with mitomycin $\mathrm{C}$ [24]. Several lines of evidence indicate that the chemosensitizing effect of the APIM-peptide is caused by the direct binding of the APIM-peptide to PCNA and that APIM-PCNA interactions are stronger under cellular stress and at least partly mediated by posttranslational modifications on PCNA [8, 10, 14, 18, 19, 22, 25].

Here we show that the APIM-peptide enhances the anti-cancer efficacy of cisplatin in a syngeneic orthotopic MIBC model in rats and increases the efficacy of GC and MVAC in a panel of human BC cell lines. The APIM-peptide-cisplatin combination reduces the expression of multiple proteins and oncogenic pathways, often upregulated in BC as well as in other solid tumors. We detect increased levels of DNA strand breaks after APIM-peptide-cisplatin treatment, suggesting that the APIM-peptide inhibits repair of cisplatin-induced lesions. Notably, the APIM-peptide re-sensitizes cisplatin-resistant $\mathrm{BC}$ cells and elevates the levels of DNA strand breaks in these cells to the same level as in cisplatin-sensitive cells.

\section{RESULTS}

\section{APIM-peptide increased the anti-cancer efficacy of cisplatin in vivo}

The anti-cancer effect of the APIM-peptide in combination with cisplatin was first examined in a MIBC model in rat. Inoculated cells were left to grow for three weeks before three rats were terminated to establish that the instilled cells had progressed to MIBC (untreated, Figure 1). Histopathological evaluation confirmed that two of these bladders had muscle invasive high grade (T2G3) tumors at this time point, while the last was classified as non-muscle invasive high grade (T1G3) (Table 1A). We therefore treated the remaining rats at this time point and evaluated treatment efficacy one week later.

Effect of the treatment was defined as bladder weight lower than the average bladder weight of the vehicle group (broken line in Figure 1). Effect of treatment was found in $100 \%$ of the combination group, compared to $81 \%$ of the cisplatin group and $43 \%$ of the APIM-peptide group (29\% in vehicle group). Importantly, the combination group had a significantly lower tumor weight $(\mathrm{p}=0.04)$ and a more uniform response to treatment than the cisplatin group (Table 1B and Figure 1). Of notice, no acute toxicity was observed in rats treated with the APIM-peptide. 
Histopathological evaluation of the bladders confirmed fewer invasive tumors $(\mathrm{T} 2 / 3 \mathrm{G} 3)$ in the combination group $(47 \%)$ than in the cisplatin group (63\%) (Table 1B). Because the initial tumor volume in individual rats prior to treatments is unknown in this model, it was difficult to establish whether bladders classified as histopathological "normal" were cured, or if they were non-takes (one in cisplatin and two in combination group, see Table 1B). However, the bladder weights were significantly lower in the combination group than in the cisplatin group even if the cured/potential non-takes were excluded $(\mathrm{p}=0.05)$. Our results suggest that the APIM-peptide can potentiate the anti-cancer efficacy of cisplatin.

To explore the biodistribution of APIM-peptide after i.v. infusion, we harvested tissue from thigh, heart, kidney, brain, liver and bladder immediately after infusion of fluorescently tagged APIM-peptides. Positive fluorescence was detected by confocal imaging in frozen sections from all organs evaluated, including the bladder, supporting that the increased anti-cancer activity of cisplatin on bladder tumors was due to the presence of the APIM-peptide (Supplementary Figure 1).

\section{Efficacy of cisplatin-containing treatments were enhanced by the APIM-peptide in vitro}

Next, we examined if the APIM-peptide could increase the sensitivity of several cisplatin-containing treatments using a panel of human BC cells. Previously, we found that the sensitivity towards the APIM-peptide as a single agent varied in these cell lines, but that this was not linked to their PCNA levels [24]. However, their sensitivities towards cisplatin were similar and, importantly, the efficacies of cisplatin, MVAC and GC were enhanced by the APIM-peptide in all cell lines (Figure 2). Our results suggest that the APIM-peptide increases the efficacies of several chemotherapeutics used for MIBC therapy.

\section{APIM-peptide-cisplatin treatment increased the number of differentially expressed (DE) genes}

We selected the Um-Uc-3 and T-24 cell lines for gene expression analysis because they represent one APIM-peptide single agent sensitive (Um-Uc-3) and one insensitive (T-24) cell line. Still, APIM-peptide treatment increased the efficacy of cisplatin in both cell lines. We only included DE genes similarly changed in all three biological replicas of both cell lines. The APIM-peptide as a single agent did not have any similar effects on gene expression in the two cell lines (Figure 3A). Cisplatin as a single agent altered gene expression of multiple genes similarly in the two cell lines, and $75 \%$ of these DE genes overlapped with those in the APIM-peptide-cisplatin treated group. However, the combination treatment resulted

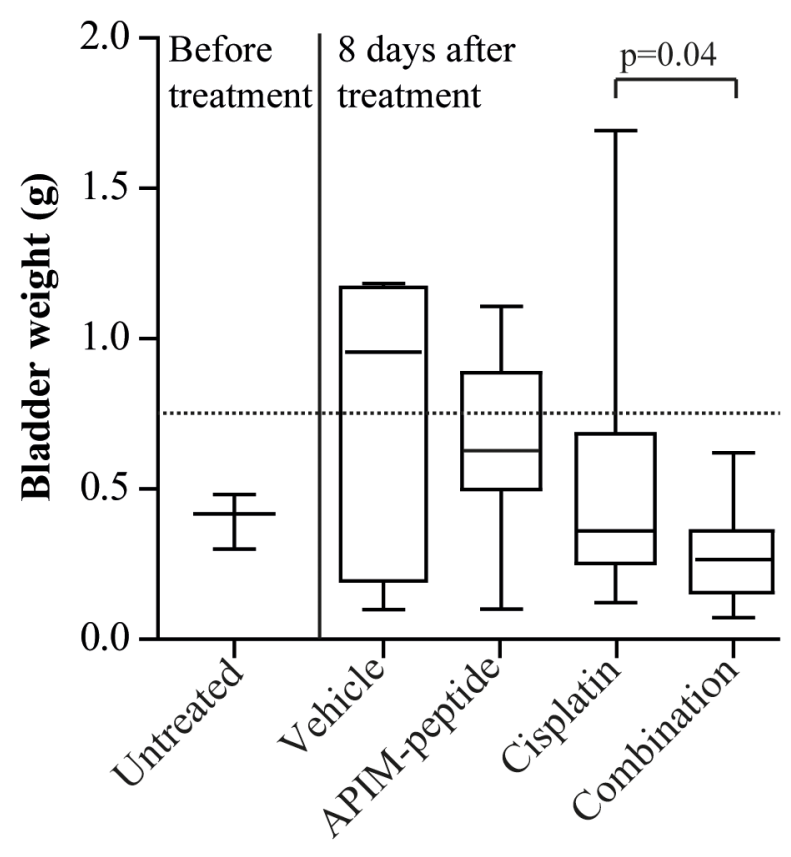

Figure 1: Combination of APIM-peptide and cisplatin therapy inhibits tumor growth in an orthotopic MIBC solid tumor model. Box-and-whisker plot of rat bladder weights harvested before treatment $(n=3)$ or eight days after intravenous treatment with vehicle ( $\mathrm{NaCl}, 0.9 \%, \mathrm{n}=7)$, APIM-peptide (8.5 and $12.5 \mathrm{mg}$ APIM-peptide peptide $/ \mathrm{kg}, \mathrm{n}=7$ ) and cisplatin $(2 \mathrm{mg} / \mathrm{kg}, \mathrm{n}=16)$ alone or in combination $(\mathrm{n}=19)$. Data from three biological replicas is included in the figure. P-values were calculated using unpaired, two-tailed student $t$-test. The line in the box is the median, the box extends from the lower to the upper quartile, and the whiskers represent the lowest and highest bladder weight in each group. 
Table 1: Histopathological classification of bladders before and after therapy

\begin{tabular}{|c|c|c|c|}
\hline \multicolumn{4}{|l|}{$\mathbf{A}$} \\
\hline Bladder weight (g) & \multicolumn{2}{|c|}{ Histological classification } & Clinical classification \\
\hline 0.30 & \multicolumn{2}{|c|}{ T2G3 } & MIBC \\
\hline 0.48 & \multicolumn{2}{|c|}{$\mathrm{T} 2 \mathrm{G} 3$} & MIBC \\
\hline 0.42 & \multicolumn{2}{|c|}{ T1G3 } & NMIBC \\
\hline \multicolumn{4}{|l|}{ B } \\
\hline Cisplatin & \multicolumn{3}{|c|}{ APIM-peptide-cisplatin } \\
\hline Bladder weight (g) & Histological classification & Bladder weight (g) & Histological classification \\
\hline 0.12 & Normal & 0.07 & TaG2 \\
\hline 0.22 & T1G3 & 0.08 & Normal \\
\hline 0.23 & T1G2 & 0.09 & Normal \\
\hline 0.23 & $\mathrm{~T} 1 \mathrm{G} 2$ & 0.12 & TaG2 \\
\hline 0.27 & $\mathrm{~T} 2 \mathrm{G} 3$ & 0.16 & TaG1 \\
\hline 0.29 & $\mathrm{~T} 1 \mathrm{G} 2$ & 0.21 & $\mathrm{~T} 2 \mathrm{G} 3$ \\
\hline 0.33 & T2G3 & 0.23 & TaG1 \\
\hline 0.36 & $\mathrm{~T} 2 \mathrm{G} 3$ & 0.24 & $\mathrm{~T} 2 \mathrm{G} 3$ \\
\hline 0.36 & T2G3 & 0.27 & T1G3 \\
\hline 0.39 & T2G3 & 0.27 & T1G3 \\
\hline 0.43 & T3G3 & 0.27 & $\mathrm{~T} 1 \mathrm{G} 2$ \\
\hline 0.57 & $\mathrm{~T} 3 \mathrm{G} 3$ & 0.31 & TaG2 \\
\hline 0.61 & TaG1 & 0.32 & $\mathrm{~T} 3 \mathrm{G} 3$ \\
\hline 0.76 & T3G3 & 0.36 & $\mathrm{~T} 2 \mathrm{G} 3$ \\
\hline 0.86 & T3G3 & 0.36 & $\mathrm{~T} 2 \mathrm{G} 3$ \\
\hline 1.69 & T3G3 & 0.41 & $\mathrm{~T} 2 \mathrm{G} 3$ \\
\hline \multirow[t]{4}{*}{ Average: 0.48} & & 0.47 & $\mathrm{~T} 2 \mathrm{G} 3$ \\
\hline & & 0.48 & T3G3 \\
\hline & & 0.62 & T3G3 \\
\hline & & Average: $\mathbf{0 . 2 8}$ & \\
\hline
\end{tabular}

Histopathological evaluation of rat bladders inoculated with AY-27 cells for three weeks at (A) treatment start and (B) 8 days after treatment with cisplatin $(2 \mathrm{mg} / \mathrm{kg})$ as single agent or in combination with APIM-peptide $(8.5 \mathrm{mg} / \mathrm{kg}$ or 12.5 $\mathrm{mg} / \mathrm{kg}$ APIM-peptide $/ \mathrm{kg}$ ). Normal bladder weight is approximately $0.1 \mathrm{~g}$, while tumor-containing bladders are heavier corresponding to size and grade of tumor [24].

in more than 1200 additional DE genes not affected by cisplatin treatment alone (combination minus shaded area, Figure 3A). The majority of these genes were downregulated $(73 \%)$. Similar trends were seen after 4 hours of treatment, but the number of DE genes were strongly increased from 4 to 24 hours (Supplementary Figure 2).

\section{Combination treatment downregulated genes frequently overexpressed in cancer}

The DE genes identified only in the combination group (orange area in Figure 3A, gene lists in Supplementary Table 1) were subjected to gene enrichment analysis. Alterations in several pathways 
A

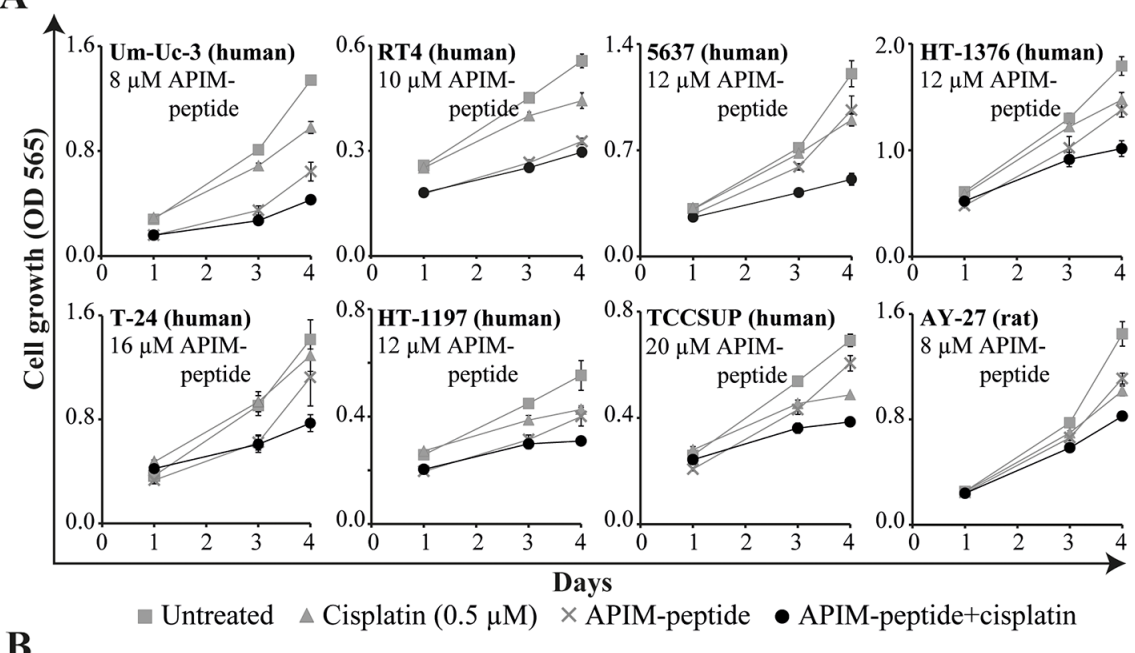

B

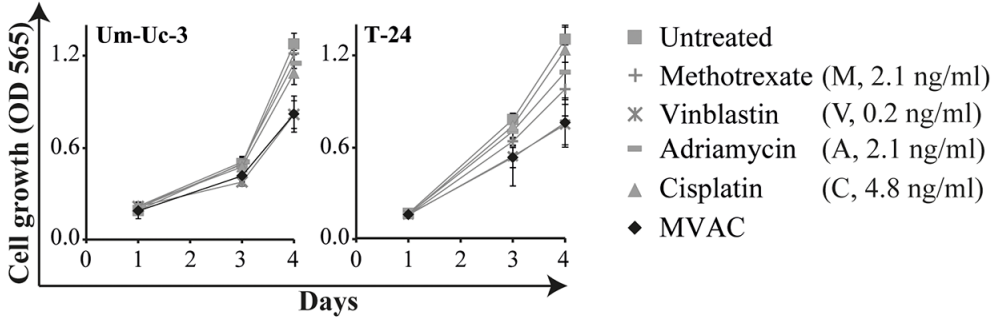

C

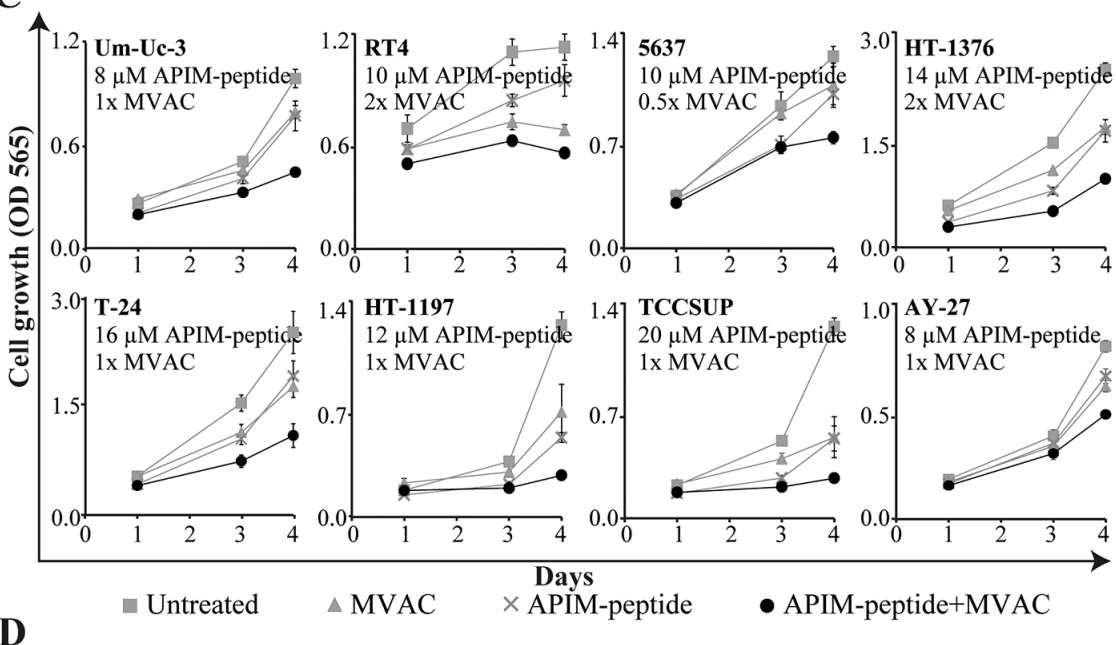

D

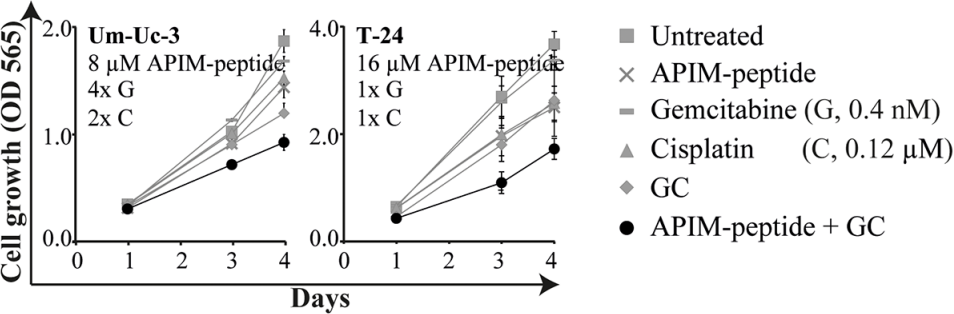

Figure 2: APIM-peptide in combination with clinically relevant cisplatin-containing combinations inhibits cell growth in vitro. Cell growth (MTT assay) of BC cell lines after continuous exposure to the APIM-peptide and chemotherapeutic agents as single agents or in combination (added on day 0). Each graph is from one representative replica of at least three biological replicas. Data is displayed as average $\pm \mathrm{SD}$ (4-6 technical replicas). (A) APIM-peptide and cisplatin as single agents and in combination. (B) Methotrexate, vinblastine, adriamycin and cisplatin as single agents and in combination (MVAC). The sensitivity to vinblastine as a single agent are similar as to MVAC. (C) APIM-peptide and MVAC (0.5-2x of the doses in (B)) alone and in combination. (D) APIM-peptide, gemcitabine and cisplatin as single agents and in combinations (GC). 
DE genes at $24 \mathrm{~h}$

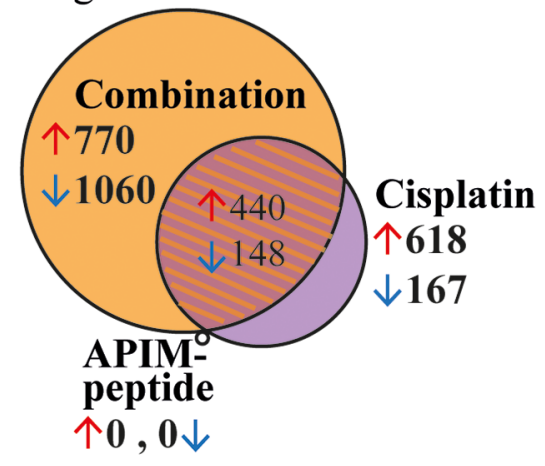

B

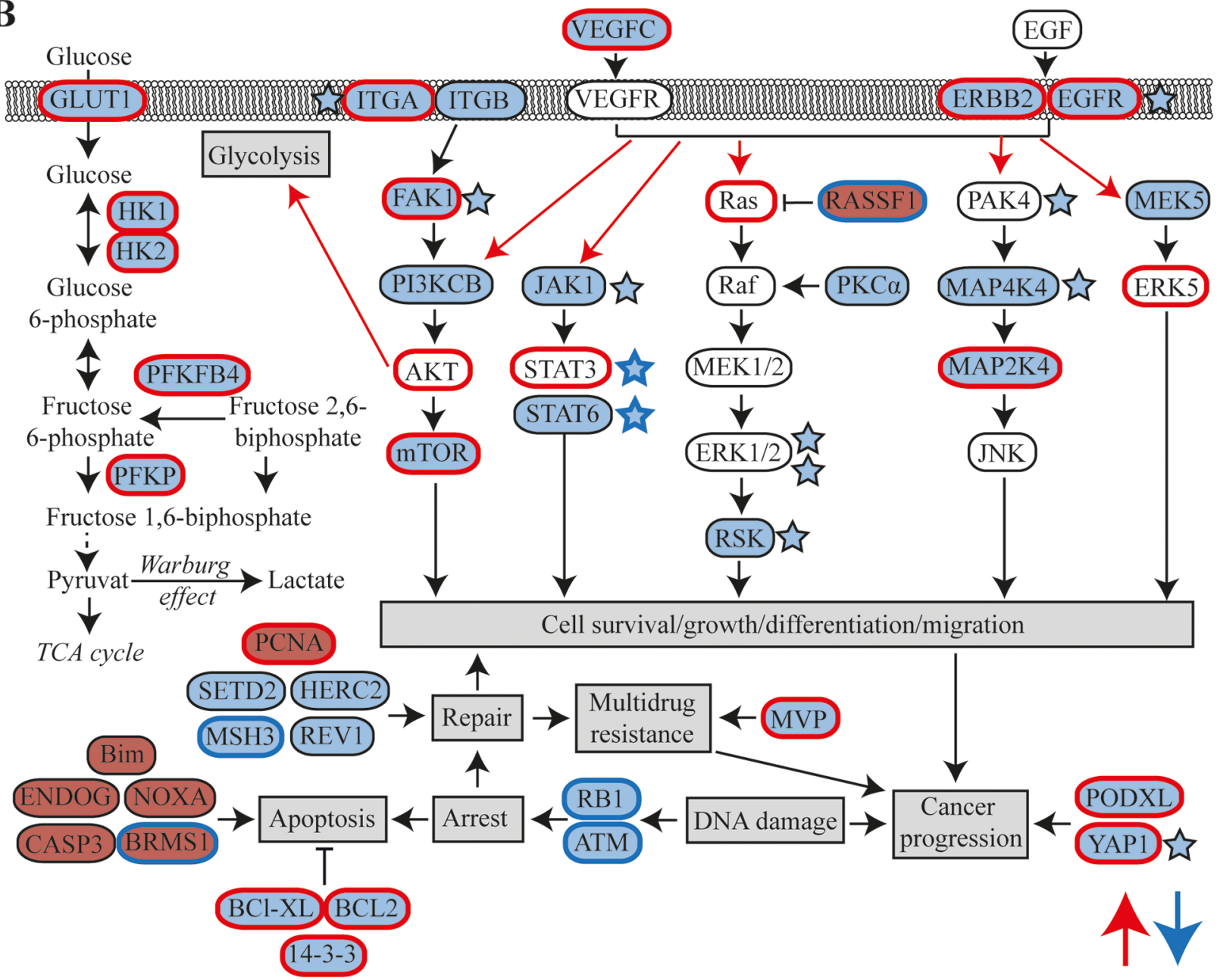

Figure 3: APIM-peptide in combination with cisplatin downregulates expression of frequently overexpressed genes in MIBC. Microarray analysis on Um-Uc-3 and T-24 cells treated for $24 \mathrm{~h}$ with APIM-peptide ( 8 and $16 \mu \mathrm{M}$, respectively) and cisplatin (10 $\mu \mathrm{M})$ alone or in combination $(\mathrm{n}=6)$. (A) Venn diagram illustrating number of differentially expressed (DE) genes in each treatment group (relative to untreated control, FC>1.25). Orange area marks the part unique for the combination group. (B) Schematic overview highlighting the most interesting upregulated (red background) and downregulated (blue background) DE genes detected only in the combination group with relevance to MIBC. Red edge $=$ often overexpressed in MIBC, blue edge $=$ often inactivated in MIBC, red arrows $=$ often upregulated pathways in MIBC [4, 26-30, 32, 33, 37, 49-54]. Stars denote downregulated proteins detected by the MIB-assay; i) only in the combination group (blue stars with blue edges) or ii) more downregulated in the combination group than the cisplatin group (blue stars black edges). 
including cell cycle, DNA damage, EGFR/VEGF signaling, transcription and apoptosis were identified (Table 2). A simplified schematic overview highlighting DE genes after combination treatment in relation to the most relevant pathways for MIBC are shown in Figure 3B. Expression of $V E G F C, E G F R, E R B B 2$ and several genes encoding proteins in downstream MAPK and PI3K/ Akt signaling pathways were downregulated. Interestingly, these are commonly overexpressed in MIBC, as well as other solid cancers [26, 27]. Furthermore, downregulation of several genes encoding proteins involved in the DNA damage response, e.g. RB1, ATM, HERC2 (NER), REV1 (TLS), MSH3 (mismatch repair) and SETD2 (homologues recombination) were detected. Downregulation of glycolysis was indicated by the reduced expression of GLUT1, HK1/2 and other glycolytic enzymes often overexpressed in BC [28]. Moreover, pro-apoptotic factors such as Bim and caspase 3 were upregulated, while antiapoptotic factors such as BCL2 and BCL-XL, commonly overexpressed in BC [26], were downregulated. Our results demonstrate that combination treatment alters key genes in MIBC that are supportive of the inhibited $\mathrm{BC}$ growth observed both in vivo (Figure 1) and in vitro (Figure 2).

\section{APIM-peptide enhanced cisplatin-induced changes in cellular signaling}

To confirm the alterations in cellular signaling indicated by gene expression analysis on protein level, we enriched the cell extracts from Um-Uc-3 and T-24 for kinases and other $\mathrm{dNTP} / \mathrm{NTP}$ interacting proteins prior to mass spectrometry (MS) analysis using the multiplexed inhibitor bead (MIB)-assay. We detected significant changes in 522 proteins after APIM-peptidecisplatin treatment compared to untreated control (Figure 4A). This included 4 phosphatases, 15 ubiquitin ligases and other proteasome/chaperone proteins as well as 32 signaling kinases. Of these proteins, 148 were unique for the combination group (orange area in Figure 4A, protein lists in Supplementary Table 2). Many of the same proteins were pulled down in all treatment groups, however, $67 \%$ of the proteins pulled down in both cisplatin and combination groups (shaded area Figure 4A) were more increased/ reduced by the combination treatment (Figure 4B). Reduced pull-down of multiple proteins in the combination group supported downregulation of the EGFR/ERBB2, MAPK and PI3K/Akt pathways as suggested by the gene expression analysis (stars in Figure 3B).

\section{APIM-peptide-cisplatin combination increased glucose and glutamine consumption and affected central carbon metabolism}

Gene expression analysis indicated that the APIMpeptide-cisplatin combination downregulates genes encoding glycolytic enzymes. To investigate whether these changes were reflected in the metabolome we next measured glucose and glutamine consumption, lactate production and applied targeted metabolic profiling of central carbon metabolism. We detected low residual glucose in Um-Uc-3 cell cultures, and even though addition of glucose in control experiments did not affect cell growth or sensitivity to treatment (Supplementary Figure 3), it could cause altered carbon metabolism. Therefore, emphasis was placed on metabolic responses in $\mathrm{T}-24$ cells, although most trends were reproduced in UmUc-3 cells (Supplementary Figure 4B, and bolded in 4C). APIM-peptide-cisplatin treatment significantly increased glucose and glutamine consumption compared to cisplatin as a single agent. Lactate excretion was increased in both cisplatin and combination treated cells, yet the lactate/ glucose ratio was decreased in combination treated cells only (Figure 5A-5B). The reduced ratio, although not significant, suggests that the APIM-peptide reduces the Warburg effect in cisplatin treated cells.

The altered glucose and glutamine consumption of cisplatin and APIM-peptide-cisplatin treated cells was reflected intracellularly by several significantly changed metabolite pool sizes (Supplementary Figure 4). Common to both treatments was increased levels of essential amino acids and deoxynucleosides, likely attributed to growth arrest and inhibition of replication. The combination treatment evoked larger changes in more metabolite pools than cisplatin as a single agent (Figure 5C, “+” in Supplementary Figure 4C). The most prominent changes were a buildup of metabolites after the rate-limiting conversion of fructose- 6 phosphate to fructose 1,6-bisphosphate in glycolysis, a reduction of the 6-phospoglyconate pool in the entry to pentose phosphate pathway (PPP) and a reduction in the $\alpha$-ketoglutarate pool of tricarboxylic acid (TCA) cycle (Supplementary Figure 4C). Altogether, the upregulated glucose and glutamine consumption, reduced lactate/glucose ratio and altered metabolite pool sizes at important metabolic branch points shows that $\mathrm{BC}$ cells undergo considerable changes in central carbon metabolism as a response to the APIMpeptide-cisplatin combination therapy. However, an exact explanation for the anti-cancer activity observed requires further studies.

\section{APIM-peptide re-sensitized cisplatin resistant cells}

Development of resistance is a major problem in cancer therapy and the mechanisms are multifactorial, including enhanced DNA repair, impaired signaling and reduced intracellular cisplatin accumulation [5]. Gene expression analysis indicated that the APIM-peptidecisplatin treatment downregulated expression of $P O D X L$, $Y A P 1$ and $M V P$ (Figure 3B); genes that are commonly overexpressed in MIBC and associated with multidrug 
Table 2: Gene enrichment indicates altered cell cycle regulation and signaling by the APIM-peptide-cisplatin combination at $24 \mathrm{~h}$

\section{Upregulated:}

\section{Cell cycle}

1.

3.

7.

10.

\section{Transcription}

2. Assembly of RNA Polymerase II preinitiation complex on TATA-less promoters

5.
Role of APC in cell cycle regulation

Transition and termination of DNA replication

Role of SCF complex in cell cycle regulation

Start of DNA replication in early $\mathrm{S}$ phase
$6 / 32$

$4 / 28$

$3 / 29$

$3 / 32$

$4 / 18$

$3 / 24$

$4 / 29$

$3 / 26$

$3 / 32$

$5 / 108$

$5 \mathrm{E}-5$

$5 \mathrm{E}-3$

$5 \mathrm{E}-2$

$5 \mathrm{E}-2$

$1.4 \mathrm{E}-3$

4E-2

5E-3

ATM / ATR regulation of G2 / M checkpoint

5E-2

ATM/ATR regulation of $\mathrm{G} 1 / \mathrm{S}$ checkpoint

CTP/UTP metabolism

$5 \mathrm{E}-2$

Downregulated:

Cytoskeleton remodeling

1.

5.

\section{Signaling}

2.

9.

\section{Development}

3.

4.

14.

16.

17.

Transport

6.

\section{Cell adhesion}

7.

19.

20.
Growth factors in regulation of oligodendrocyte precursor cell survival

PIP3 signaling in cardiac myocytes

EGFR signaling via small GTPases

VEGF signaling via VEGFR2 - generic cascades

Cytokine-mediated regulation of megakaryopoiesis
$16 / 111$

$14 / 102$

4E-4

Cytoskeleton remodeling

9E-4

$9 / 36$

4E-4

$8 / 39$

3E-3

$9 / 37$

4E-4

$10 / 47$

$4 \mathrm{E}-4$

$7 / 33$

$3 \mathrm{E}-3$

$11 / 84$

$3 \mathrm{E}-3$

9/57

$3 \mathrm{E}-3$

$11 / 71$

2E-3

Clathrin-coated vesicle cycle

Chemokines and adhesion

$13 / 100$

2E-3

$8 / 45$

$3 \mathrm{E}-3$

$8 / 45$

$3 \mathrm{E}-3$

(Continued) 


\section{Neurophysiological process}

8. Main pathways of Schwann cells transformation in neurofibromatosis type $1 \quad 10 / 62 \quad 2 \mathrm{E}-3$

18.

Receptor-mediated axon growth repulsion

$8 / 45$

$3 \mathrm{E}-3$

Muscle-contraction

10.

$\mathrm{S} 1 \mathrm{P} 2$ receptor-mediated smooth muscle contraction

$7 / 30$

$3 \mathrm{E}-3$

Translation

11.

Translation regulation by Alpha-1 adrenergic receptors

$9 / 53$

$3 \mathrm{E}-3$

Apoptosis and survival

$3 \mathrm{E}-3$

12.

BAD phosphorylation

$8 / 42$

$3 \mathrm{E}-3$

13.

Anti-apoptotic action of Gastrin

$8 / 43$

$3 \mathrm{E}-3$

Cell cycle

15.

ESR1 regulation of G1/S transition

$7 / 33$

$3 \mathrm{E}-3$

List of all significant upregulated and top 20 significant downregulated GeneGo pathway maps. The gene enrichment analysis were done on the differentially expressed genes (fold change $>1.25$ relative to control, and found in all six biological replica of Um-Uc-3 and T-24 cells) unique for the APIM-peptide-cisplatin combination group, and not detected in cisplatin or APIM-peptide single agent groups (lists of genes in Supplementary Table 1). The GeneGo pathway maps are grouped by their main category.

resistance $[4,29,30]$. We therefore developed a cisplatin resistant Um-Uc-3 cell line (Um-Uc-3-R) and investigated the effect of the APIM-peptide on cisplatin sensitivity in this cell line. Um-Uc-3-R, cells were more resistant to cisplatin compared to original Um-Uc-3 cells at all doses tested and importantly, the APIM-peptide increased the sensitivity of both Um-Uc-3 and Um-Uc-3-R cells (Figure $6 \mathrm{~A}$, viability after 48 hours exposure). For instance, the viability of Um-Uc-3-R cells was not reduced by $2 \mu \mathrm{M}$ cisplatin, while the viability of Um-Uc-3 cells was reduced with $20 \%$ at this time point. However, when combined with the APIM-peptide, the Um-Uc-3-R cells were resensitized to this dose of cisplatin (Figure 6A).

To explore the molecular mechanism behind this sensitizing effect, we examined if the APIM-peptide increased the levels of DNA lesions by impairing DNA repair in cisplatin treated cells. All treatments significantly increased the level of DNA damage relative to untreated control in both original Um-Uc-3 and cisplatin-resistant Um-Uc-3-R cells. In accordance with lower cisplatin sensitivity, Um-Uc-3-R cells had lower levels of DNA damage than Um-Uc-3 cells treated with the same dose of cisplatin after 24 hours (Figure 6B). However, the combination of cisplatin and APIM-peptide increased the amount of DNA damage in both these two cell lines and leveled out the differences between them. This indicates that at least part of the APIM-peptide re-sensitizing effect is mediated via inhibition of DNA repair. Multiple APIM-containing proteins, such as XPA and polymerase $\zeta$, are directly involved in bypass or repair of cisplatininduced DNA lesions and could be inhibited by APIMpeptide treatment, in support for this finding. Furthermore, expression of HERC2 and REV1, also important for NER and TLS, were downregulated in combination treated cells (Figure $3 \mathrm{~B}$ ) and could also contribute to the increased level of DNA lesions observed.

Next we analyzed Um-Uc-3 and Um-Uc-3-R cells for cell cycle effects and fraction of apoptotic cells upon treatment with cisplatin and the cisplatin-APIMpeptide combination. Both cell lines were arrested to the same extent in S-phase and no significant changes could be detected between the cell lines after 24 hours (Supplementary Figure 5A). The APIM-peptide increased the fraction of apoptotic cells after cisplatin treatment in Um-Uc-3 while apoptosis was not affected by any of the treatments in Um-Uc-3-R cells (Supplementary Figure 5B). Thus, there is no direct link between increased level of DNA damage induced by the combination treatment and an increase in apoptosis in the Um-Uc-3-R cells at 24 hours. Both the cisplatin alone and the combination treatment did cause a small reduction in viability for both cell lines at this time point, and in accordance with the apoptosis data it was greater for Um-Uc-3 than for the Um-Uc-3-R cells (Supplementary Figure 5C). The reduction in viability and difference between the cell lines was further enhanced after 48 hours (Figure 6A, 10 $\mu \mathrm{M}$ cisplatin), suggesting a delayed and/or reduced DDR response in the Um-Uc-3-R cells. 


\section{DISCUSSION}

Our results demonstrate that the PCNA-interacting APIM-peptide increases the anti-cancer efficacy of cisplatin in vivo by reducing tumor load and down staging $\mathrm{BC}$, and thus has the potential to improve MIBC therapy. This is supported by previous work showing that the
APIM-peptide is able to increase the efficacy of mitomycin $\mathrm{C}$ on non-MIBC [24]. Furthermore, this study reveals DE of apoptotic genes, changes in glycolytic enzymes and metabolites, and alterations in several signaling pathways often involved in oncogenic transformation when cisplatin is combined with the APIM-peptide. The exact same changes were not identified on all omics levels, however,
A

Changed proteins at $24 \mathrm{~h}$

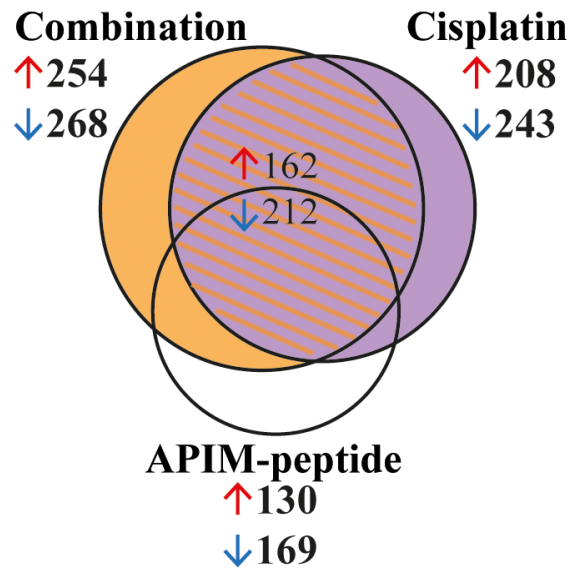

B

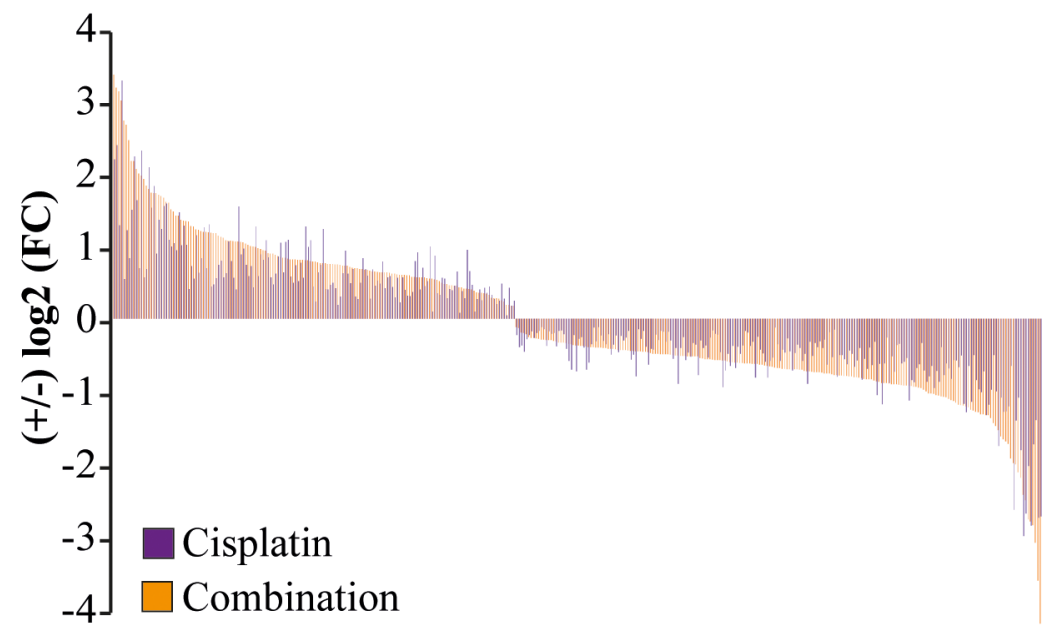

Figure 4: APIM-peptide enhances protein changes induced by cisplatin. Significantly changed proteins measured using the MIB-assay (Wilcoxon Sign Rank test, $\mathrm{p}<0.25$ ) in Um-Uc-3 and T-24 cells treated for $24 \mathrm{~h}$ with APIM-peptide ( 8 and $16 \mu \mathrm{M}$, respectively) and cisplatin $(10 \mu \mathrm{M})$ (relative to untreated control). (A) Venn diagram illustrating the number of changed proteins in each treatment group. (B) Log2 fold change (FC) of proteins detected in both cisplatin and the combination group. Each protein presented by one bar, only proteins with $>5 \%$ difference in relative values of combination (orange bars) vs cisplatin (purple bars) are shown.

A

Glucose Glutamine Lactate

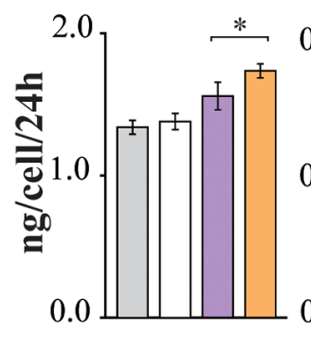

Untreated
B

Lactate/Glucose

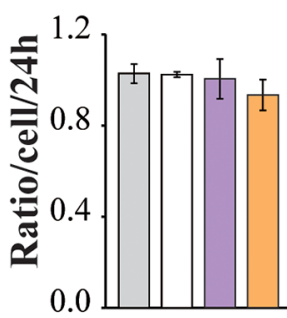

Combination
C

Altered metbolite pools at $24 \mathrm{~h}$

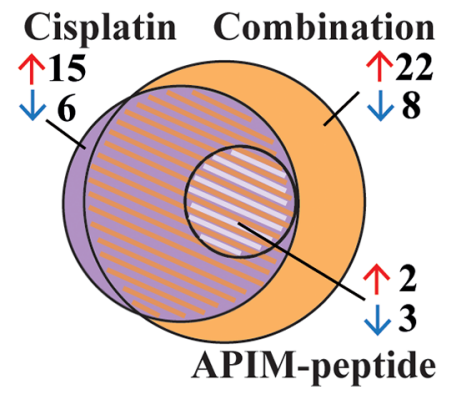

Figure 5: APIM-peptide-cisplatin combination increases energy source consumption and affects central carbon metabolism. Consumption/excretion of extracellular metabolites and targeted metabolic profiling of T-24 cells treated for 24 hours with APIM-peptide $(16 \mu \mathrm{M})$, cisplatin $(10 \mu \mathrm{M})$ and the combination $(\mathrm{n}=4)$. (A) Glucose and glutamine consumption and lactate excretion per live cell per 24 hours in each treatment group \pm SD. Significant ( $\left.{ }^{*}<<0.05\right)$ and non-significant (ANOVA and post hoc Tukey's range test) differences between cisplatin and APIM-peptide-cisplatin treated cells are indicated. Combination and cisplatin treated cells were significantly different from untreated control in all, while APIM-peptide single agent treatment was not (not marked in figure). (B) Lactate/ glucose ratio per live cell per 24 hours in each treatment group \pm SD. (C) Venn diagram illustrating the number of significantly (ANOVA and post hoc Tukey's range test, $\mathrm{p}<0.05$ ) changed intracellular central carbon metabolite pools relative to control) in each treatment group. 
this was expected because the genome, proteome and metabolome are highly dynamic, and not necessarily in phase at a given time point. Further, we discuss only a subset of the altered genes, proteins and metabolites in our data sets because exploring the complete systembiological effects of treatment via integrating all omics levels requires dedicated computational tools. Time series and further computational analysis will be the focus of future work. Yet, we demonstrate that many predicted therapeutic targets in BC are affected by the APIMpeptide-cisplatin treatment on more than one omic level, and that the changes observed are in in accordance with the observed in vivo and in vitro anti-cancer effects.

In this study, we show that APIM-peptide-cisplatin treatment leads to changed expression of multiple proteins implicated in cancer cell growth and development of cisplatin resistance. Combination treated cells reduced the expression of genes encoding proteins in the DNA damage response, both in cellular signaling, NER and TLS, and had increased levels of DNA damage. In addition to the changes in gene expression, the APIM-peptide likely directly inhibits NER and TLS as APIM-containing protein in these pathways are dependent on interaction with PCNA for optimal function [18, 22]. EGFR, ERBB2 and members of the downstream PI3K/Akt and Ras pathways are potential therapeutic cancer targets, and they were all downregulated by the combination treatment. Mutations in these pathways are found in over $40 \%$ of BC tumors and inhibitors of these are suggested to restore cisplatin sensitivity $[4,31]$. It is difficult to determine whether it is the direct inhibition of NER or TLS, or the effects on the EGFR/ERBB2 and downstream pathways or both that is responsible for the re-sensitization of cisplatin resistant cells observed after APIM-peptide-cisplatin treatment. Most likely the re-sensitizing effect is a combination of multiple factors.

The APIM-peptide-cisplatin combination also reduced the levels of $J A K$, STAT and FAK1 expression. STAT3 and FAK1 activation are reported to be important in multiple cancer types, including BC $[32,33]$. Although several inhibitors targeting EGFR, MAPK, FAK1 or $\mathrm{PI} 3 \mathrm{~K} / \mathrm{Akt}$ pathways are undergoing clinical trials for MIBC therapy, no drug has yet been approved for BC treatment [32, 34-36]. RASSF1 is suggested to have tumor suppressor functions through inhibition of the Ras pathway. Reduced expression due to hypermethylation is frequently observed in $\mathrm{BC}(\sim 80 \%)$, and is associated with progression and shorter overall survival [37]. Interestingly,
A

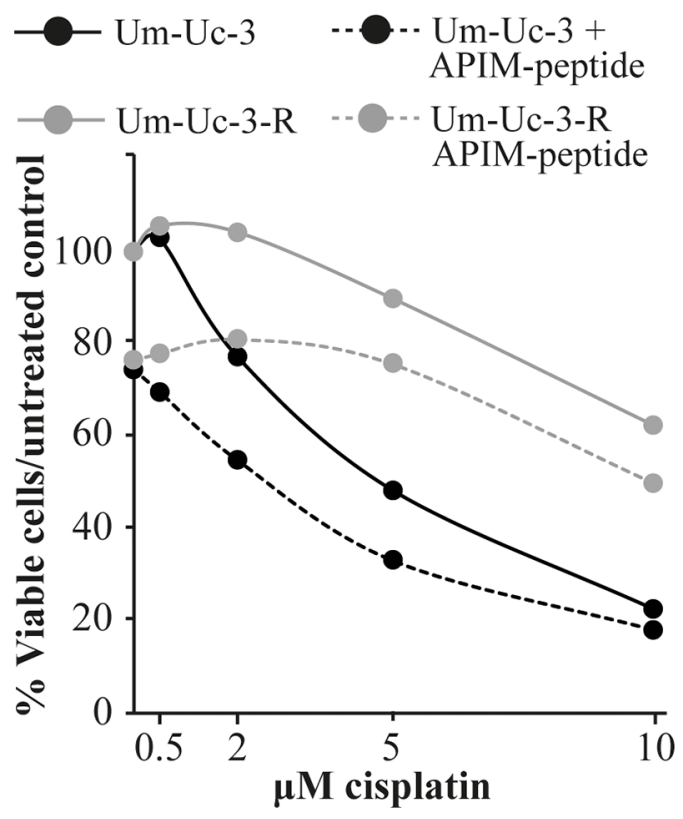

B

Um-Uc-3

Um-Uc-3-R

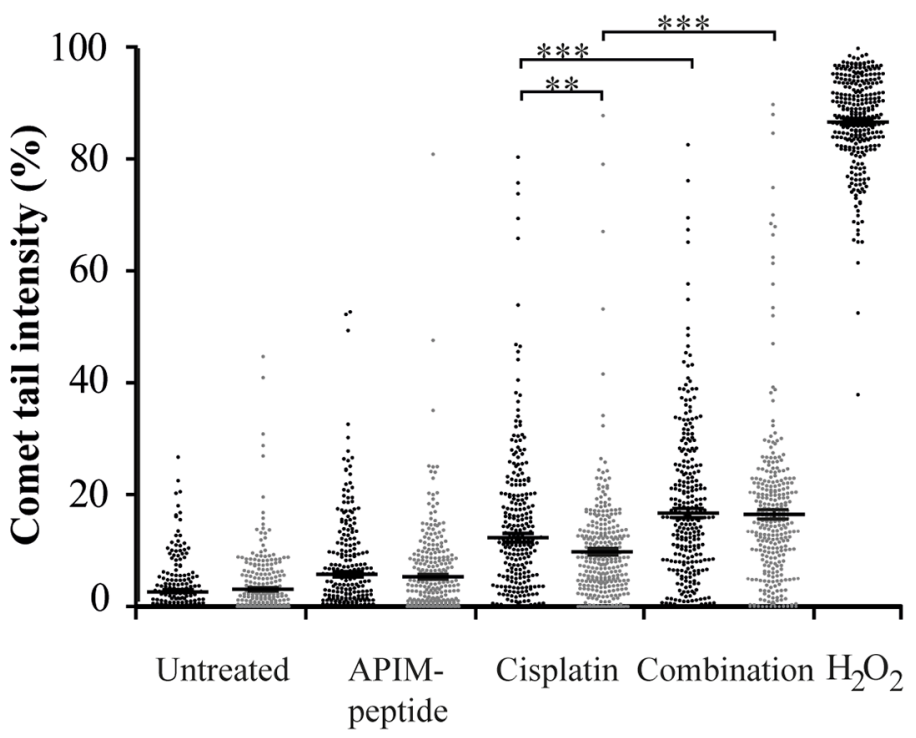

Figure 6: APIM-peptide re-sensitizes cisplatin-resistant cells. Original Um-Uc-3 and cisplatin-resistant Um-Uc-3-R cells treated with the APIM-peptide $(8 \mu \mathrm{M})$ and cisplatin (A: $0.5-10 \mu \mathrm{M}, \mathbf{B}: 10 \mu \mathrm{M})$. (A) Dose-response of treated cells relative to untreated cells measured by the MTT assay after 48 hours of continuous exposure to treatments. Data presented is one representative experiment out of at least three biological replicas. (B) Percentage tail intensity of comets from alkaline comet assay analysis after $24 \mathrm{~h}$ exposure to treatments. $\mathrm{H}_{2} \mathrm{O}_{2}(100 \mathrm{mM})$ was used as positive control. Data is merged from three biological replica in which 100 comets were randomly selected from each experiment $(\mathrm{n}=300)$, and presented as scatter plot with mean \pm SEM. ${ }^{* *} \mathrm{p}<0.01,{ }^{* * *} \mathrm{p}<0.0001$ (student- $t$ test, two tailed). All treatments were significantly $\left({ }^{* * *}\right)$ different from untreated control, and all single treatments were significantly $\left({ }^{* * *}\right)$ different from combination treatments (not marked in Figure). 
the APIM-peptide-cisplatin treatment increased RASSF1 expression. This effect could be mediated via inhibition of PCNA's role in signaling, however, many proteins involved in regulation of DNA methylations e.g. the TETproteins and DNA methyl transferases contain PCNA interacting motifs [14]. Therefore, increased RASSF1 could also be due to APIM-peptide mediated inhibition of DNA methylation.

It is not straightforward to predict the most prominent effects of the APIM-peptide in specific cancer cells because more than 300 proteins involved in multiple signaling and DNA damage pathways contain APIM. All of these potential PCNA interactions might be more or less impaired, although not identically in cells of different origin. The dependence on, and regulation of, different cellular pathways varies between cells of different tissue origins, as well as between normal and cancer cells. In any case, targeting PCNA with the APIM-peptide has the potential to affect, i.e. partly impair, but not completely inhibit, multiple pathways important in cellular stress responses simultaneously. Because cancer cells are more dysregulated and often lack normal check point regulation, this stress-confined treatment strategy is shown to have larger impact on cancer cells than normal cells across a range of cancer subtypes $[8,10]$. This treatment strategy is less likely to be circumvented by development of resistance because it targets multiple pathways, and by itself targets TLS and therefore reduces mutagenicity [22].
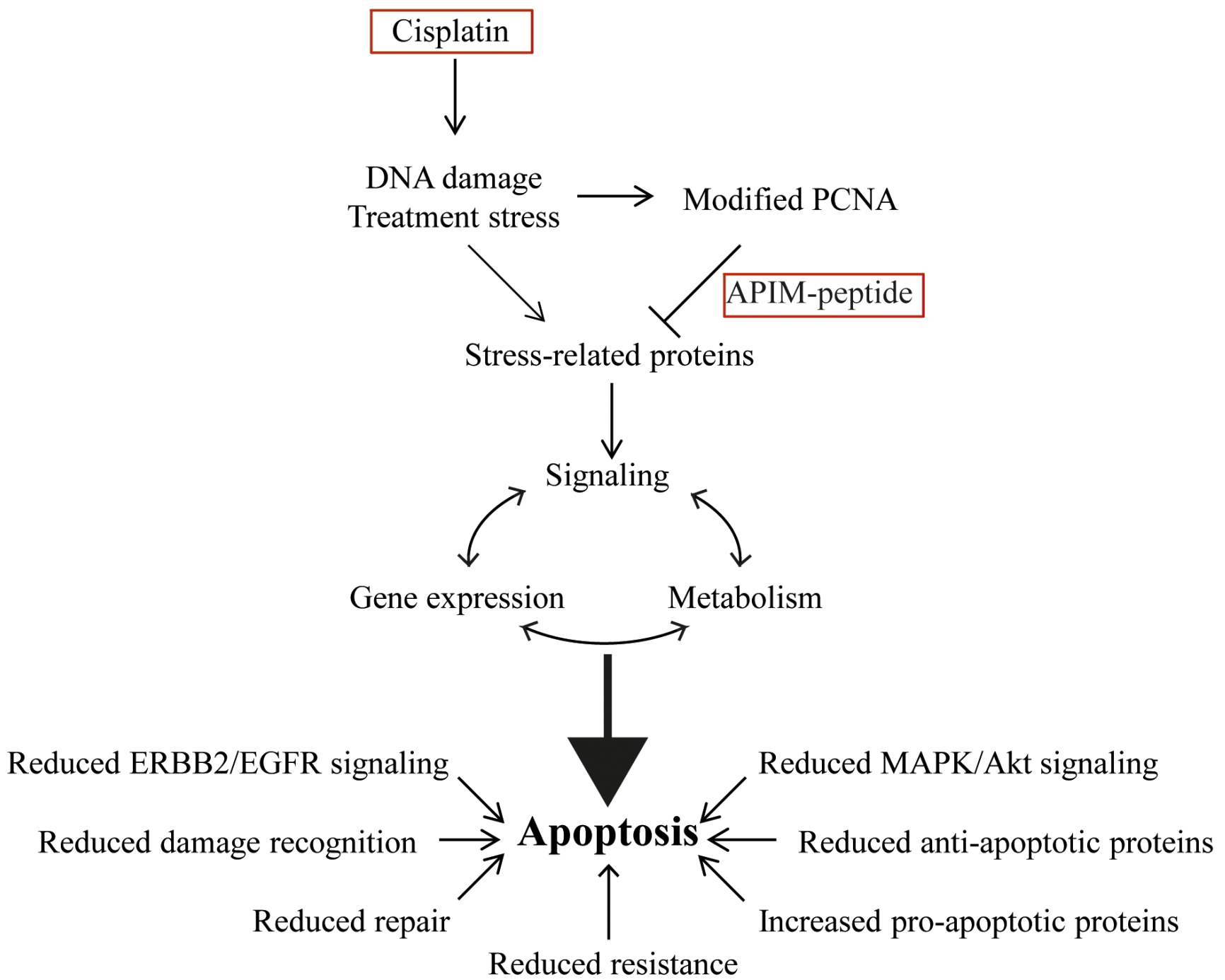

Figure 7: Combination therapy of cisplatin and APIM-peptide produce multiple effects driving the cells towards apoptosis. Cisplatin introduces DNA damage and treatment stress that increases the affinity of APIM-containing proteins for PCNA. The APIM-peptide inhibits these interactions, producing alterations in the cells signaling, gene expression profile and metabolism that ultimately pushes the cells towards apoptosis. Reduced EGFR/ERBB2, MAPK and AKT signaling, reduced damage recognition and DNA repair, reduced cisplatin resistance, reduced energy charge and increased expression of pro-apoptotic factors are all contributing to the APIM-peptide-cisplatin combinations mode of action in bladder cancer cells. 


\section{MATERIALS AND METHODS}

\section{Cell lines}

The syngeneic rat urothelial carcinoma cell line AY-27 used in the in vivo studies was kindly provided by Professor S. Selman, Department of Urology, Medical College of Ohio and grown as described [38]. A panel consisting of the human urothelial carcinoma cell lines TCCSUP, HT-1197, Um-Uc-3, HT-1376, RT4, T-24 and 5637 (ATCC No. TCP-1020) were used for the in vitro studies. All cells were grown as recommended and cultivated in a humidified atmosphere $\left(5 \% \mathrm{CO}_{2}, 37^{\circ} \mathrm{C}\right)$. Additionally, a cisplatin resistant $\mathrm{Um}-\mathrm{Uc}-3$ cell line (Um-Uc-3-R) were established by continuously exposing the cells to increasing doses of cisplatin over one year (0.0625-1 $\mu \mathrm{M}$ cisplatin, added twice a week).

\section{Treatment agents}

APIM-peptide (ATX-101, MD-RWLVK-WKKKRK-I-RRRRRRRRRRR) (APIM Therapeutics, Bachem) [10], cisplatin (Hospira), methotrexate (Pfizer), vinblastine (Velbe), adriamycin (Pfizer), gemcitabine (Santa Cruz Biotechnology) and hydrogen peroxide (Sigma-Aldrich).

\section{Animals and ethics}

The study was approved by the Norwegian National Animal Research Authority (Forsøksdyrutvalget, FDU) (FOTS applications 5502 and 6842) and in accordance with Norwegian and EU guidelines for care and use of laboratory animal.

Female CDF344 rats (Harlan Laboratories, Blackthorn) were kept in a standardized environment. Rats were anesthetized (subcutaneously) with a mixture $(0.35-0.40 \mathrm{~mL} / 100 \mathrm{~g}$ body weight $(\mathrm{BW}))$ consisting of haloperidol $(5 \mathrm{mg} / \mathrm{mL}$, Janssen) $(17 \% \mathrm{v} / \mathrm{v})$, fentanyl (50 $\mu \mathrm{g} / \mathrm{mL}$, Actavis) $(25 \% \mathrm{v} / \mathrm{v})$ and midazolam $(5 \mathrm{mg} /$ $\mathrm{mL}$, Actavis) $(25 \% \mathrm{v} / \mathrm{v})$ before orthotopic implantation. After implantation, the rats received $\mathrm{NaCl}(0.9 \%, 5-10$ $\mathrm{mL})$ and temgesic $(0.3 \mathrm{mg} / \mathrm{mL}, 0.33 \mathrm{~mL} / 200 \mathrm{~g} \mathrm{BW}$, RB Pharmaceuticals Ltd.) subcutaneously if needed, as judged by their condition. Intravenous (i.v.) treatment was performed under general anesthesia with isoflurane (4\% induction, $1.5-2 \%$ maintenance). Anaesthetized rats were kept on a heat blanket to maintain body temperature. The rats were monitored for general health status and BW throughout the duration of the experiments.

\section{In vivo MIBC model}

The in vivo studies were performed with an immunocompetent rat orthotopic $\mathrm{BC}$ model previously described with the instillation of $4 \times 10^{5} \mathrm{AY}-27$ rat $\mathrm{BC}$ cells $[38,39]$. The rats were kept for three weeks to establish muscle-invasive tumors before treatment [40]. The rats were randomly distributed into treatment groups; i) vehicle $(\mathrm{NaCl}, 0.9 \%)$, ii) APIM-peptide ( 8.5 or $12.5 \mathrm{mg}$ net APIM-peptide $/ \mathrm{kg}$ ), iii) cisplatin $(2 \mathrm{mg} / \mathrm{kg}$ ) and iv) APIM-peptide-cisplatin combination. First, cisplatin was given intravenously with a syringe $(0.4 \mathrm{~mL}$ over $2 \mathrm{~min})$, and the APIM-peptide was given subsequently via i.v. infusions using a pump (Aleris Guardrails Rolle) to ensure accuracy $(2.4 \mathrm{~mL} / \mathrm{h}, 12.5 \mathrm{mg} / \mathrm{kg} \mathrm{BW} / \mathrm{mL}$ ) (rats in vehicle and cisplatin group were given saline infusions). The rats were treated once and the bladders were harvested after eight days. The bladders were macroscopically evaluated, weighed and stored in buffered formaldehyde solution (4\%) until processing for histopathological evaluation. Statistical significance between the cisplatin and APIMpeptide-cisplatin groups was calculated using student $t$-test (unpaired, two-tailed, $\mathrm{p}<0.05$ ).

In total, 57 rats from three independent biological replicas were used in this study. Of these, 5 rats are not included in Figure 1: i) three rats died before treatment, ii) one $\mathrm{NaCl}$-treated rat died due to large tumor, iii) one rat was terminated before treatment due to reduced health status. The APIM-peptide and cisplatin combination treated groups with 8.5 or $12.5 \mathrm{mg}$ APIM-peptide $/ \mathrm{kg}$ were combined as there were no difference between these two groups.

\section{Histopathological assessment}

Paraffin embedding followed by slicing of formalinfixed bladders and hematoxylin-erythrosine (HE) staining were done using standard procedures at Cellular \& Molecular Imaging Core Facility NTNU. HE stained tissues were examined for morphological changes by an uropathologist using a light microscope (Nikon Eclipse 80i).

\section{Cell viability assay}

Cell viability (MTT-assay) was measured as previously described [14]. Data is reported as average \pm $\mathrm{SD}$ of at least four technical replicas. Data is from one representative experiment out of at least three with similar results.

\section{In vitro cell treatments for microarray, MIB-assay, mass spectrometric metabolic profiling, quantification of extracellular metabolites and comet assay}

Um-Uc-3 and T-24 cells were seeded $\left(3-4 \times 10^{6}\right.$ cells $/ 15 \mathrm{~cm}$ plate) and treated with APIM-peptide ( $8 \mu \mathrm{M}$ (Um-Uc-3) and $16 \mu \mathrm{M}(\mathrm{T}-24))$ and cisplatin $(10 \mu \mathrm{M})$ alone or in combination the next day (three treatment groups and one untreated control per cell line). Extracts from three 
individual biological replicas (done on different days) were prepared after 24 hours (h) for all conditions of each cell line. The doses were chosen based on the MTT data and the doses given intravenously to rats in the in vivo studies $(\sim 1 / 10$ of this dose).

\section{Microarray- analysis}

Samples were prepared as previously described [23]. The microarray experiments have been deposited in the ArrayExpress database (http://www.ebi.ac.uk/ arrayexpress) under accession number E-MTAB-5644. Gene expression data was normalized and analyzed using GeneSpring 12.6-GX (Agilent Technologies). DE genes were selected by comparing treated samples to untreated controls, and filtered by flags and fold change $\geq 1.25$. Lists of up- and downregulated genes identified in all three biological replicas of both Um-Uc-3 and T-24 cell lines $(n=3+3)$, and unique for the combination group (not in common with cisplatin group) were extracted. The GeneGo database (MetaCore) was used to annotate these lists of DE genes to gene ontology (GO) pathways.

\section{MIB-assay}

Total cell extracts were prepared as previously described [8]. Kinase enrichment was performed and eluted peptides were analyzed by Orbitrap MS as previously described [41]. The MS proteomics data has been deposited to the ProteomeXchange Consortium (http://proteomecentral.proteomexchange.org) via the PRIDE [42] partner repository with the data set identifier (PXD008724). Label-free quantification values were logtransformed with the base 2 and the transformed control values were subtracted. The resulting values reflecting the change relative to control for each condition were subjected to two-sided Wilcoxon Sign Rank Test [43] as implemented in MATLAB R2015a (Mathworks Inc.). Proteins with p-value $<0.25$ were considered significantly changed. Three biological replicas were analyzed for each of the treatments. Proteins exhibiting the same trends in both T-24 and Um-Uc-3 cells, and significantly changed in at least one of the cell lines, were selected.

\section{Quantification of extracellular metabolites}

Supernatants were collected, lyophilized and upconcentrated four times in deuterium oxide (Sigma-Aldrich). $1 \mathrm{D}$ proton spectra were recorded at $25^{\circ} \mathrm{C}$ on a Bruker Ascend $400 \mathrm{MHz}$ Avance III HD equipped with a $5 \mathrm{~mm}$ Z-gradient SmartProbe (Bruker). The anomeric proton of $\alpha$-glucose (5.2 ppm), methyl $\mathrm{H} \beta$ of lactate $(1.3 \mathrm{ppm})$ and methylene $\mathrm{H} \gamma$ of glutamine (2.4 ppm) were integrated and quantified by electronic reference to access in vivo concentrations (ERETIC2, Topspin 3.5, Bruker). The methylamine $\mathrm{H}$ of a creatine $(3.0 \mathrm{ppm})$ external standard (Sigma-Aldrich) was defined as the ERETIC reference. Consumption/production was normalized to average number of live cells (average of live cell density when treatment was initiated and live cell density at time of harvest) within the $24 \mathrm{~h}$ time interval examined to obtain consumption/production /cell/24h. Four independent cultures of Um-Uc-3 and T-24 cells were analyzed for each condition.

\section{Targeted mass spectrometric metabolic profiling}

Cells were sampled as described in [44], transferred directly to liquid nitrogen and extracted and up-concentrated as described in [45]. Phosphorylated metabolites were prepared for and analyzed by capillary ion chromatography (capIC)-MS/MS as described in [44]. Organic acids were derivatized as described in [46] prior to analysis by liquid chromatography (LC)-MS/MS. Derivatized samples (5 $\mu \mathrm{l})$ were injected onto a Waters Aquity BEH C ${ }_{18} 2.1$ x 100 mm column, maintained at $40^{\circ} \mathrm{C}$ and eluted with mobile phases (A) water added $0,1 \%$ formic acid and (B) methanol. The following gradient $(\mathrm{v} / \mathrm{v} \%)$ was applied with a flow rate of $0.25 \mathrm{ml} / \mathrm{min}$ : 0-0.5 min; 50\% B, 0.5-6 min: 50-99\% B, 6-7 min: 99\% B, 7-7.1 min: 100-50\% B, 8 min: end. Amino acids were derivatized by a protocol adapted from [47], making use of propyl chloroformate and n-propanol, and analyzed by LC-MS/MS. Derivatized samples $(1 \mu \mathrm{l})$ were injected onto a Phenomenex EZ faast AAA-MS 250 x $0.2 \mathrm{~mm}$ column maintained at $25^{\circ} \mathrm{C}$ and eluted with mobile phases (A) water and (B) methanol, both added $10 \mathrm{mM}$ ammonium formate. The following gradient (v/v \%) was applied with a flow rate of $0.25 \mathrm{ml} / \mathrm{min}$ : $0-1 \mathrm{~min}$ : $68 \% \mathrm{~B}, 1-11 \mathrm{~min}$ : $68-85 \%$ B, 11-11.5min: 85-68\% B, 15 min: end. Both LC-MS/MS analyses were performed on a Waters AQUITY UPLC/Xevo TQ-S MS system operated in positive electrospray mode. Absolute quantification from a dilution series of external standards (organic and amino acids, Sigma-Aldrich) was performed in MassLynx V4.1 (Waters). LC-MS/MS analysis was performed for four independent cultures per condition from three biological replicas, capIC-MS/MS analysis was performed for four independent cultures per condition. Metabolome concentrations/abundances were normalized to total ion intensity and tested for significant differences between treatment groups by ANOVA and post hoc Tukey's range test $(\mathrm{p}<0.05)$.

\section{Alkaline comet assay}

Single-cell gel electrophoresis (comet assay) detecting DNA single and double strand breaks, alkalilabile sites, interstrand crosslinks and incomplete excision repair sites, were performed as previously described [48] with minor modifications: Harvested cells were suspended in low melting agarose $\left(1 \%, 10^{5}\right.$ cells $\left./ \mathrm{mL}\right)$ and spread on CometAssay ${ }^{\circledR}$ HT slides (Trevigen) $(40 \mu \mathrm{L})$ in technical duplicates for each condition. Samples were incubated in lysis buffer overnight $\left(4^{\circ} \mathrm{C}\right)$ and in alkaline solution $(\mathrm{pH}>13,60 \mathrm{~min})$ before gel electrophoresis $(0.3 \mathrm{~A}, 30$ $\mathrm{min})$. The slides were washed in neutralization buffer 
(0.4M Tris- $\mathrm{HCl})$, fixed in ethanol and stained with SYBR $^{\circledR}$ Green I (Sigma-Aldrich) before analysis using the Comet Assay IV software (Perceptive Instruments). Cells treated with hydrogen peroxide (100 mM, 20 $\min , 4^{\circ} \mathrm{C}$ ) were used as a positive control. Fifty comets from each technical duplicate were randomly selected and analyzed for each condition (100 comets) in each biological experiment. Data for all three biological replica is presented (300 comets), and average \pm SEM is given. Statistical significance between groups were calculated by student $t$-test (unpaired, two-tailed, ${ }^{* *} \mathrm{p}<0.01,{ }^{* * *} \mathrm{p}<0.0001$ ).

\section{CONCLUSIONS}

In this study we demonstrate an increased anticancer efficacy of cisplatin when combined with the PCNA-targeting APIM-peptide, both in vitro in human $\mathrm{BC}$ cell lines and in vivo in the MIBC model. Our results suggest that several key genes and pathways relevant for multiple solid tumors, including MIBC, are affected after treatment with the APIM-peptide-cisplatin combination. In particular, reduced EGFR/ERBB2 signaling, reduced repair of cisplatin-induced DNA damage, re-sensitization of cisplatin-resistant cells and increased apoptosis were features of the combination treatment (summarized in Figure 7). All these changes contribute to the increased anti-cancer efficacy observed for the combination treatment. In conclusion, our results suggest that the APIM-peptide has the potential to improve cisplatintherapy in the clinical setting and cause an increased anti-cancer response less likely to be circumvented by resistance.

\section{Abbreviations}

APIM- AlkB homologue 2 PCNA interacting motif; BC- Bladder cancer; DE- Differentially expressed; GCGemcitabine and cisplatin; MIB-assay- Multiplexed inhibitor bead assays; MIBC- Muscle invasive bladder cancer; MVAC- Methotrexate, vinblastine, adriamycin and cisplatin; NER- Nucleotide excision repair; PCNAProliferating cell nuclear antigen; TLS- Translesion synthesis.

\section{Author contributions}

Study design: CKS, AB, LMR, CJA, PB and MO; Data collection: CKS, AB, LMR, VP, AN, SB, NBL, OAG, TV, MO;

Writing of manuscript: CKS, AB, LMR, CJA and MO.

\section{ACKNOWLEDGMENTS}

Technical assistance for animal experiments and animal care was provided by the Comparative Medicine Core Facility (CoMed), NTNU. The histological staining of bladder samples was provided by Kathrin Torseth at the Cellular and Molecular Imaging Core Facility (CMIC), NTNU. The microarray gene expression service was provided by the Genomics Core Facility (GCF), NTNU. The proteomic analysis at the Proteomic and Metabolomics Core Facility (PROMEC), NTNU. We would like to thank Animesh Sharma for help with the data collection for the MIB-assay and Silje Malene Olsen, Marit Otterlei Fjørtoft, Yngve Forsland and Renathe Haugdahl Nøst for technical assistance in cell cultivation and sample processing for metabolic profiling. CoMed, CMIC, PROMEC and GCF are funded by the Faculty of Medicine at NTNU and Central Norway Regional Health Authority. The mass spectrometric metabolic profiling and quantification of extracellular metabolites was performed at the NTNU NV-faculty's MS and NMR facilities, respectively.

\section{CONFLICTS OF INTEREST}

APIM Therapeutics is a spin-off company of the Norwegian University of Science and Technology, and has co-funded this study. Professor Marit Otterlei is an inventor, minority shareholder and CSO of this company. Patent application no: PCT/GB2009/000489 "New PCNA interacting motif”, filed on February 20, 2009. There are no further patents, products or development or marked products to declare. The other authors declare no conflict of interest.

\section{FUNDING}

We acknowledge support from Joint Research Committee between St. Olavs and Faculty of Medicine and Health Science, NTNU, The liaison Committee for education, research and innovation in Central Norway, Norwegian University of Science and Technology (NTNU), Norwegian Research Council, APIM Therapeutics (financing a $50 \% \mathrm{PhD}$ position for 1 year) and Norwegian Cancer Society. The funding sources had no other roles or involvement in this research.

\section{REFERENCES}

1. Antoni S, Ferlay J, Soerjomataram I, Znaor A, Jemal A, Bray F. Bladder cancer incidence and mortality: a global overview and recent trends. Eur Urol. 2017; 71:96-108. https://doi.org/10.1016/j.eururo.2016.06.010.

2. Witjes JA, Compérat E, Cowan NC, De Santis M, Gakis G, Lebret T, Ribal MJ, Van der Heijden AG, Sherif A, and European Association of Urology. EAU guidelines on muscle-invasive and metastatic bladder cancer: summary of the 2013 guidelines. Eur Urol. 2014; 65:778-92. https://doi.org/10.1016/j.eururo.2013.11.046. 
3. Davarpanah NN, Yuno A, Trepel JB, Apolo AB. Immunotherapy: a new treatment paradigm in bladder cancer. Curr Opin Oncol. 2017; 29:184-95. https://doi.org/10.1097/CCO.0000000000000366.

4. Cancer Genome Atlas Research Network. Comprehensive molecular characterization of urothelial bladder carcinoma. Nature.2014;507:315-22.https://doi.org/10.1038/nature12965.

5. Siddik ZH. Cisplatin: mode of cytotoxic action and molecular basis of resistance. Oncogene. 2003; 22:7265-79. https://doi.org/10.1038/sj.onc.1206933.

6. von der Maase H, Sengelov L, Roberts JT, Ricci S, Dogliotti L, Oliver T, Moore MJ, Zimmermann A, Arning M. Long-term survival results of a randomized trial comparing gemcitabine plus cisplatin, with methotrexate, vinblastine, doxorubicin, plus cisplatin in patients with bladder cancer. J Clin Oncol. 2005; 23:4602-08. https://doi.org/10.1200/JCO.2005.07.757.

7. Moldovan GL, Pfander B, Jentsch S. PCNA, the maestro of the replication fork. Cell. 2007; 129:665-79. https://doi.org/10.1016/j.cell.2007.05.003.

8. Olaisen C, Müller R, Nedal A, Otterlei M. PCNAinteracting peptides reduce Akt phosphorylation and TLRmediated cytokine secretion suggesting a role of PCNA in cellular signaling. Cell Signal. 2015; 27:1478-87. https://doi.org/10.1016/j.cellsig.2015.03.009.

9. Witko-Sarsat V, Mocek J, Bouayad D, Tamassia N, Ribeil JA, Candalh C, Davezac N, Reuter N, Mouthon L, Hermine O, Pederzoli-Ribeil M, Cassatella MA. Proliferating cell nuclear antigen acts as a cytoplasmic platform controlling human neutrophil survival. J Exp Med. 2010; 207:2631-45. https://doi.org/10.1084/jem.20092241.

10. Müller R, Misund K, Holien T, Bachke S, Gilljam KM, Våtsveen TK, Rø TB, Bellacchio E, Sundan A, Otterlei M. Targeting proliferating cell nuclear antigen and its protein interactions induces apoptosis in multiple myeloma cells. PLoS One. 2013; 8:e70430. https://doi.org/10.1371/journal.pone.0070430.

11. Naryzhny SN, Lee $H$. Proliferating cell nuclear antigen in the cytoplasm interacts with components of glycolysis and cancer. FEBS Lett. 2010; 584:4292-98. https://doi.org/10.1016/j.febslet.2010.09.021.

12. Wang SC. PCNA: a silent housekeeper or a potential therapeutic target? Trends Pharmacol Sci. 2014; 35:178-86. https://doi.org/10.1016/j.tips.2014.02.004.

13. Warbrick E. PCNA binding through a conserved motif. BioEssays. 1998; 20:195-99. https://doi. org/10.1002/(SICI)1521-1878(199803)20:3<195::AIDBIES2>3.0.CO;2-R.

14. Gilljam KM, Feyzi E, Aas PA, Sousa MM, Müller R, Vågbø CB, Catterall TC, Liabakk NB, Slupphaug G, Drabløs F, Krokan HE, Otterlei M. Identification of a novel, widespread, and functionally important PCNA-binding motif. J Cell Biol. 2009; 186:64554. https://doi.org/10.1083/jcb.200903138.
15. Norwegian University of Science and Technology. Bioinformatics and Gene Regulation, Supplementary material for Giljam/Olaisen et al.

16. Olaisen C, Kvitvang HF, Lee S, Almaas E, Bruheim P, Drabløs F, Otterlei M. The role of PCNA as a scaffold protein in cellular signaling is functionally conserved between yeast and humans. FEBS Open Bio. 2018; 8:113545. https://doi.org/10.1002/2211-5463.12442.

17. Warbrick E. A functional analysis of PCNA-binding peptides derived from protein sequence, interaction screening and rational design. Oncogene. 2006; 25:2850 59. https://doi.org/10.1038/sj.onc.1209320.

18. Gilljam KM, Müller R, Liabakk NB, Otterlei M. Nucleotide excision repair is associated with the replisome and its efficiency depends on a direct interaction between XPA and PCNA. PLoS One. 2012; 7:e49199. https://doi.org/10.1371/journal.pone.0049199.

19. Ciccia A, Nimonkar AV, Hu Y, Hajdu I, Achar YJ, Izhar L, Petit SA, Adamson B, Yoon JC, Kowalczykowski SC, Livingston DM, Haracska L, Elledge SJ. Polyubiquitinated PCNA recruits the ZRANB3 translocase to maintain genomic integrity after replication stress. Mol Cell. 2012; 47:396-409. https://doi.org/10.1016/j.molcel.2012.05.024.

20. Bacquin A, Pouvelle C, Siaud N, Perderiset M, SaloméDesnoulez S, Tellier-Lebegue C, Lopez B, Charbonnier JB, Kannouche PL. The helicase FBH1 is tightly regulated by PCNA via CRL4(Cdt2)-mediated proteolysis in human cells. Nucleic Acids Res. 2013; 41:6501-13. https://doi.org/10.1093/nar/gkt397.

21. Fattah FJ, Hara K, Fattah KR, Yang C, Wu N, Warrington $\mathrm{R}$, Chen DJ, Zhou P, Boothman DA, Yu H. The transcription factor TFII-I promotes DNA translesion synthesis and genomic stability. PLoS Genet. 2014; 10:e1004419. https://doi.org/10.1371/journal.pgen.1004419.

22. Ræder SB, Nepal A, Bjørås KØ, Seelinger M, Kolve RS, Nedal A, Müller R, Otterlei M. Direct REV3LPCNA interaction is important for the specificity of DNA translesion synthesis. Submitted 2018.

23. Søgaard CK, Moestue SA, Rye MB, Kim J, Nepal A, Liabakk NB, Bachke S, Bathen TF, Otterlei M, Hill DK. APIM-peptide targeting PCNA improves the efficacy of docetaxel treatment in the TRAMP mouse model of prostate cancer. Oncotarget. 2018; 9:11752-66. https://doi.org/10.18632/oncotarget.24357.

24. Gederaas OA, Søgaard CD, Viset T, Bachke S, Bruheim P, Arum CJ, Otterlei M. Increased Anticancer Efficacy of Intravesical Mitomycin C Therapy when Combined with a PCNA Targeting Peptide. Transl Oncol. 2014; 7:812-23. https://doi.org/10.1016/j.tranon.2014.10.005.

25. Sebesta M, Cooper CD, Ariza A, Carnie CJ, Ahel D. Structural insights into the function of ZRANB3 in replication stress response. Nat Commun. 2017; 8:15847. https://doi.org/10.1038/ncomms15847. 
26. Cheng L, Davison DD, Adams J, Lopez-Beltran A, Wang L, Montironi R, Zhang S. Biomarkers in bladder cancer: translational and clinical implications. Crit Rev Oncol Hematol. 2014; 89:73-111. https://doi.org/10.1016/j.critrevonc.2013.08.008.

27. Knowles MA, Hurst CD. Molecular biology of bladder cancer: new insights into pathogenesis and clinical diversity. Nat Rev Cancer. 2015; 15:25-41. https://doi.org/10.1038/nrc3817.

28. Yang X, Cheng Y, Li P, Tao J, Deng X, Zhang X, Gu M, Lu Q, Yin C. A lentiviral sponge for miRNA-21 diminishes aerobic glycolysis in bladder cancer T24 cells via the PTEN/PI3K/AKT/mTOR axis. Tumour Biol. 2015; 36:38391. https://doi.org/10.1007/s13277-014-2617-2.

29. Boman K, Larsson AH, Segersten U, Kuteeva E, Johannesson H, Nodin B, Eberhard J, Uhlén M, Malmström PU, Jirström K. Membranous expression of podocalyxinlike protein is an independent factor of poor prognosis in urothelial bladder cancer. Br J Cancer. 2013; 108:2321-28. https://doi.org/10.1038/bjc.2013.215.

30. Diestra JE, Condom E, Del Muro XG, Scheffer GL, Pérez J, Zurita AJ, Muñoz-Seguí J, Vigués F, Scheper RJ, Capellá G, Germà-Lluch JR, Izquierdo MA. Expression of multidrug resistance proteins P-glycoprotein, multidrug resistance protein 1 , breast cancer resistance protein and lung resistance related protein in locally advanced bladder cancer treated with neoadjuvant chemotherapy: biological and clinical implications. J Urol. 2003; 170:1383-87. https://doi.org/10.1097/01.ju.0000074710.96154.c9.

31. Galluzzi L, Senovilla L, Vitale I, Michels J, Martins I, Kepp O, Castedo M, Kroemer G. Molecular mechanisms of cisplatin resistance. Oncogene. 2012; 31:186983. https://doi.org/10.1038/onc.2011.384.

32. Ho PL, Lay EJ, Jian W, Parra D, Chan KS. Stat3 activation in urothelial stem cells leads to direct progression to invasive bladder cancer. Cancer Res. 2012; 72:3135-42. https://doi.org/10.1158/0008-5472.CAN-11-3195.

33. Kong DB, Chen F, Sima N. Focal adhesion kinases crucially regulate TGF $\beta$-induced migration and invasion of bladder cancer cells via Src kinase and E-cadherin. OncoTargets Ther. 2017; 10:1783-92. https://doi.org/10.2147/OTT.S122463.

34. Mooso BA, Vinall RL, Mudryj M, Yap SA, deVere White RW, Ghosh PM. The role of EGFR family inhibitors in muscle invasive bladder cancer: a review of clinical data and molecular evidence. J Urol. 2015; 193:19-29. https://doi.org/10.1016/j.juro.2014.07.121.

35. Carneiro BA, Meeks JJ, Kuzel TM, Scaranti M, Abdulkadir SA, Giles FJ. Emerging therapeutic targets in bladder cancer. Cancer Treat Rev. 2015; 41:170-78. https://doi.org/10.1016/j.ctrv.2014.11.003.

36. Soria JC, Gan HK, Blagden SP, Plummer R, Arkenau HT, Ranson M, Evans TR, Zalcman G, Bahleda R, Hollebecque A, Lemech C, Dean E, Brown J, et al. A phase I, pharmacokinetic and pharmacodynamic study of
GSK2256098, a focal adhesion kinase inhibitor, in patients with advanced solid tumors. Ann Oncol. 2016; 27:2268-74. https://doi.org/10.1093/annonc/mdw427.

37. Bilgrami SM, Qureshi SA, Pervez S, Abbas F. Promoter hypermethylation of tumor suppressor genes correlates with tumor grade and invasiveness in patients with urothelial bladder cancer. Springerplus. 2014; 3:178. https://doi.org/10.1186/2193-1801-3-178.

38. Larsen EL, Randeberg LL, Gederaas OA, Arum CJ, Hjelde A, Zhao CM, Chen D, Krokan HE, Svaasand LO. Monitoring of hexyl 5-aminolevulinate-induced photodynamic therapy in rat bladder cancer by optical spectroscopy. J Biomed Opt. 2008; 13:044031. https://doi.org/10.1117/1.2967909.

39. Xiao Z, McCallum TJ, Brown KM, Miller GG, Halls SB, Parney I, Moore RB. Characterization of a novel transplantable orthotopic rat bladder transitional cell tumour model. Br J Cancer. 1999; 81:638-46. https://doi.org/10.1038/sj.bjc.6690741.

40. Arum CJ, Anderssen E, Viset T, Kodama Y, Lundgren $\mathrm{S}$, Chen D, Zhao CM. Cancer immunoediting from immunosurveillance to tumor escape in microvillus-formed niche: a study of syngeneic orthotopic rat bladder cancer model in comparison with human bladder cancer. Neoplasia. 2010; 12:434-42. https://doi.org/10.1593/neo.91824.

41. Petrovic V, Olaisen C, Sharma A, Nepal A, Bugge S, Sundby E, Hoff BH, Slupphaug G, Otterlei M. On-column trypsinization allows for re-use of matrix in modified multiplexed inhibitor beads assay. Anal Biochem. 2017; 523:10-16. https://doi.org/10.1016/j.ab.2017.01.027.

42. Vizcaíno JA, Csordas A, del-Toro N, Dianes JA, Griss J, Lavidas I, Mayer G, Perez-Riverol Y, Reisinger F, Ternent T, Xu QW, Wang R, Hermjakob H. 2016 update of the PRIDE database and its related tools. Nucleic Acids Res. 2016; 44:D447-56. https://doi.org/10.1093/nar/gkv1145.

43. Gibbons JD, Chakraborti S. Nonparametric statistical inference. International encyclopedia of statistical science. Springer; 2011. pp. 977-9. https://doi.org/10.1007/978-3-642-04898-2_420.

44. Kvitvang HF, Kristiansen KA, Bruheim P. Assessment of capillary anion exchange ion chromatography tandem mass spectrometry for the quantitative profiling of the phosphometabolome and organic acids in biological extracts. J Chromatogr A. 2014; 1370:70-79. https://doi.org/10.1016/j.chroma.2014.10.029.

45. Kvitvang HF, Bruheim P. Fast filtration sampling protocol for mammalian suspension cells tailored for phosphometabolome profiling by capillary ion chromatography - tandem mass spectrometry. J Chromatogr B Analyt Technol Biomed Life Sci. 2015; 998-999:45-49. https://doi.org/10.1016/j.jchromb.2015.06.018.

46. Tan B, Lu Z, Dong S, Zhao G, Kuo MS. Derivatization of the tricarboxylic acid intermediates with O-benzylhydroxylamine for liquid chromatography-tandem 
mass spectrometry detection. Anal Biochem. 2014; 465:134-47. https://doi.org/10.1016/j.ab.2014.07.027.

47. Kvitvang HF, Kristiansen KA, Lien SK, Bruheim P. Quantitative analysis of amino and organic acids by methyl chloroformate derivatization and GC-MS/ MS analysis. Methods Mol Biol. 2014; 1198:137-45. https://doi.org/10.1007/978-1-4939-1258-2_10.

48. Bosshard M, Aprigliano R, Gattiker C, Palibrk V, Markkanen E, Backe PH, Pellegrino S, Raymond FL, Froyen G, Altmeyer M, Bjørås M, Dianov GL, van Loon B. Impaired oxidative stress response characterizes HUWE1promoted X-linked intellectual disability. Sci Rep. 2017; 7:15050. https://doi.org/10.1038/s41598-017-15380-y.

49. Yun SJ, Jo SW, Ha YS, Lee OJ, Kim WT, Kim YJ, Lee SC, Kim WJ. PFKFB4 as a prognostic marker in non-muscleinvasive bladder cancer. Urologic Oncology: Seminars and Original Investigations. Elsevier; 2012. pp. 893-9.

50. Sakaguchi T, Yoshino H, Yonemori M, Miyamoto K, Sugita S, Matsushita R, Itesako T, Tatarano S, Nakagawa M, Enokida H. Regulation of ITGA3 by the dual-stranded microRNA-199 family as a potential prognostic marker in bladder cancer. Br J Cancer. 2017; 116:1077-87. https://doi.org/10.1038/bjc.2017.43.
51. Noguchi S, Mori T, Hoshino $\mathrm{Y}$, Maruo K, Yamada N, Kitade Y, Naoe T, Akao Y. MicroRNA-143 functions as a tumor suppressor in human bladder cancer T24 cells. Cancer Lett. 2011; 307:21120. https://doi.org/10.1016/j.canlet.2011.04.005.

52. Herbsleb M, Christensen OF, Thykjaer T, Wiuf C, Borre M, Ørntoft TF, Dyrskjøt L. Bioinformatic identification of FGF, p38-MAPK, and calcium signalling pathways associated with carcinoma in situ in the urinary bladder. BMC Cancer. 2008; 8:37. https://doi.org/10.1186/1471-2407-8-37.

53. Seraj MJ, Harding MA, Gildea JJ, Welch DR, Theodorescu D. The relationship of BRMS1 and RhoGDI2 gene expression to metastatic potential in lineage related human bladder cancer cell lines. Clin Exp Metastasis. 2000; 18:519-25. https://doi.org/10.1023/A:1011819621859.

54. Kawakami T, Shiina H, Igawa M, Deguchi M, Nakajima K, Ogishima T, Tokizane T, Urakami S, Enokida H, Miura K, Ishii N, Kane CJ, Carroll PR, Dahiya R. Inactivation of the hMSH3 mismatch repair gene in bladder cancer. Biochem Biophys Res Commun. 2004; 325:93442. https://doi.org/10.1016/j.bbrc.2004.10.114. 